\title{
The Prevalence of Open and Closed Posterior Superior lliac Spine
}

\author{
Eray ATLI, Sadik Ahmet UYANIK, Umut OGUSLU, Halime CEVIK CENKERI, Birnur YILMAZ, Burcak GUMUS \\ Okan University Hospital, Department of Radiology, Tuzla, Istanbul, Turkey
}

Corresponding author: Eray ATLI atlieray@gmail.com

\section{ABSTRACT}

AIM: To determine the prevalence of open and closed posterior superior iliac spine (PSIS) using lower abdominal computed tomography (CT) examinations.

MATERIAL and METHODS: Eight hundred and fifty (M/F:464/386) adult patients who underwent lower abdominal CT between January 2018 and December 2018 were evaluated retrospectively. One radiologist reviewed CT images of patient pelvises to assess the presence of open and closed PSIS.

RESULTS: The mean age of all patients was $52.7 \pm 18$ years. Of the 850 patients, 522 (61.5\%) had open PSIS, while 328 (38.5\%) had closed PSIS. The distribution of open and closed PSIS by gender was $57.5 \%$ and $42.5 \%$ in males and $66 \%$ and $34 \%$ in females, respectively.

CONCLUSION: Overall, open PSIS is more common than closed PSIS. The closed PSIS is seen more often in males than in females. If an anteromedial sacral (S)-1 screw direction is chosen for posterior fusion with rod-screw fixation, it is essential to obtain CT images for evaluation of PSIS.

KEYWORDS: Computed tomography, Posterior superior iliac spine (PSIS), Open PSIS, Closed PSIS, S1 screwing

ABBREVIATIONS: CT: Computed tomography, PSIS: Posterior superior iliac spine, PACS: Picture Archiving Communication Systems, SPSS: Statistical package for social sciences

\section{INTRODUCTION}

$\mathrm{T}$ To provide stability for the lumbosacral spine, posterior fusion with rod-screw fixation is commonly used in degenerative spondylolisthesis, fractures of vertebrae, scoliosis, and primary and metastatic tumors of the spine (4). For sacral 1 (S1) screwing for posterior lumbosacral rodscrew fixation, variable approaches can be used, including anteromedial (transpedicular or pediculocorporeal), anterior, anterolateral (lateral mass), and anteroinferior directions $(3,4,6,10,11,14)$. Open and closed posterior superior iliac spine (PSIS), described by Kaptanoglu et al. (6), are 2 important anatomical variations in sacral spinal surgery. If PSIS is located lateral to the pediculocorporeal screw direction line, it is called open PSIS (Figure 1A, B). An open PSIS allows safe and secure S1 screwing anteromedially from the superior articular $\mathrm{S} 1$ facet when using a posterior approach. On the other hand, if the PSIS is medial to the pediculocorporeal screw direction line, which is a closed $P S I S$, it is difficult to insert a S1 screw anteromedially from the superior articular $\mathrm{S} 1$ facet using a posterior approach (Figure 2A, B). For a closed PSIS, Kaptanoglu et al. recommended resection before S1 screwing in the anteromedial direction (6). Therefore, it is essential to determine the relationship between the sacrum and PSIS (open or closed) before surgery, during the radiological evaluation; however, there is a lack of data in the literature concerning closed and open PSIS. This single

\begin{tabular}{llll}
\hline Eray ATLI & (1) : :0000-0002-2639-9924 & Halime CEVIK CENKERI (i) : 0000-0003-1622-7501 \\
Sadik Ahmet UYANIK (1) : 0000-0003-0622-2985 & Birnur YILMAZ & (1) : 0000-0001-8624-5807 \\
Umut OGUSLU & (D) : :0000-0001-7985-0734 & Burcak GUMUS & (1) : 0000-0002-3933-7263
\end{tabular}


center study aimed to determine the prevalence of open and closed PSIS by evaluating lower abdominal computed tomography (CT) scans of patients, which were performed for various reasons.

\section{MATERIAL and METHODS}

A total of 850 (464 male) adult patients ( $\geq 18$ years old) who underwent lower abdominal CT between January 2018 and December 2018 were included in this retrospective study. If the patient had more than 1 CT scan of the relevant region, only 1 CT was included in the study. Ethics committee approval was obtained and the requirement for informed consent was waived by the ethics committee (Protocol no: 2019/19). One radiologist with 10 years of experience reviewed CT images of pelvises retrieved from the Picture Archiving Communication Systems (PACS). The images were assessed for the presence of open or closed PSIS.

\section{Statistical Analysis}

Categorical variables were expressed as numbers and percentages. Numeric variables were expressed as means and standard deviation. Variables were compared using the chi-squared test and the Mann-Whitney $U$ test. The statistical package for social sciences (SPSS) version 21 (SPSS Inc.) was used for statistical analysis. A value of $p<0.05$ was considered statistically significant.

\section{RESULTS}

The mean age of all patients was $52 \pm 18$ years. Neither open nor closed PSIS groups had a significant difference in terms of age (Figure 3 ) ( $p>0.05)$. Five hundred and twenty-two patients (61.5\%) had open PSIS, while 328 patients (38.5\%) had closed PSIS. In male patients (464), open PSIS was detected in 267 (57.5\%), and closed PSIS was detected in 197 (42.5\%). In female patients (386), open PSIS was detected in 255 (66\%), and closed PSIS was detected in 131 (34\%) (Figure 4). There was a significant difference between both groups regarding gender $(p=0.01)$. The closed PSIS was more common in males compared to females.

\section{DISCUSSION}

In this study, open PSIS was found in $61.5 \%$ of patients, and closed PSIS was found in $38.5 \%$ of patients, regardless of sex. In male patients, $42.5 \%$ had closed PSIS, while in female patients, 34\% had closed PSIS.

Kaptanoglu et al. evaluated a total of 50 PSIS cases in 25 adult cadaver pelvises (15 male and 10 female) (6). They found that males are more prone to closed PSIS than females $(34 \%$ of male and $25 \%$ of female specimens), which is consistent with our findings.

Higher prevalence of closed PSIS in males compared to females is most likely associated with pelvic anatomy. The differences between male and female bony pelvises are due to adaptive changes of the female pelvis for childbearing. The female pelvis is larger and broader than the male pelvis, whereas the male pelvis is narrower, longer, and more compact. The sacrum in females is shorter, wider, and more curved posteriorly, whereas the sacrum in males is taller, narrower, and straighter. In addition, the sacral promontory and muscle attachments in the male are more prominent in comparison to the female (13).

Different methods have been suggested for S1 screwing in lumbosacral fusion $(5,7-10,15,17)$. Two screw directions are typically used: either the anteromedial direction, which is tracked from the sacral pedicle to promontory, or the anterolateral direction, which is tracked from the sacral pedicle to the sacral wing. It has been reported that screwing in the anteromedial direction is biomechanically better than screwing in the anterolateral direction $(1,12)$. Anteromedial S1 screwing is secure and has excellent anchoring because the screw passes through and terminates in dense bone $(2,3,5)$.

Open PSIS allows safe and secure anteromedial S1 screw insertion, whereas closed PSIS is problematic because it does not allow S1 screw insertion in an anteromedial direction. In this situation, the screw terminates laterally in the unsafe zone. In the anteromedial S1 screw direction, the safe area where the screw is to be terminated is promontory medially, the internal iliac vein laterally (approximately $25 \mathrm{~mm}$ wide), and the promontory superiorly by $20 \mathrm{~mm}$ (12), in front of promontory as well (16). Out of this safe zone, the lumbosacral trunk, internal iliac artery and vein, and sacroiliac joint are the structures that can be injured during S1 screw insertion. In closed PSIS, it is recommended that the ilium is resected first to provide a more anteromedial trajectory for $\mathrm{S} 1$ pedicle screwing, as well as to avoid possible complications (6). Hence, screws terminate at the anterior part of the S1 sacral vertebral body or promontory, which is a denser and stronger part of the bone. Furthermore, because bilateral S1 screwing anteromedially forms a triangulation of the screws, a pull-out resistance mechanism is formed (7). Moreover, resected bone from closed PSIS can be used as auto-graft material when grafting and fusion are necessary during posterior lumbosacral instrumentation procedures.

Preoperatively obtained CT scans help to assess PSIS variations, and the amount of iliac resection can also be determined by CT scan. This technique is becoming more prevalent with the increasing availability of CT machines that can obtain isovolumetric data. We recommend thin axial CT sections (1 or $1.25 \mathrm{~mm}$ ) of the lumbosacral region, as well as sagittal and coronal plane reformatted images from those thin sections.

One limitation in this study was that the study group consisted of patients who underwent lower abdominal CT daily. This may be insufficient for sampling the population, but due to radiation exposure concerns, CT scans should not be performed in the general population, only in the search for open and closed PSIS.

\section{CONCLUSION}

Overall, open PSIS is more common than closed PSIS. The closed PSIS is seen more often in males than in females. When 

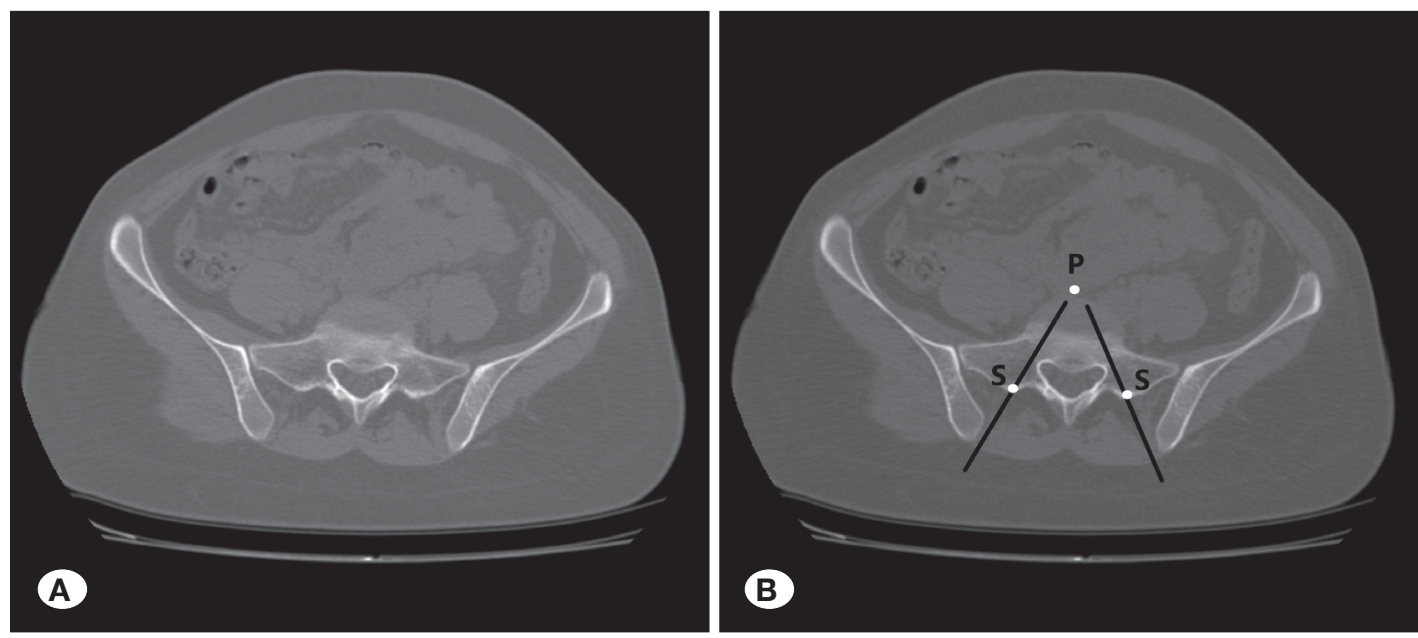

Figure 1: (A) and (B) (marked). Open posterior superior iliac spine (PSIS) is shown in axial computed tomography (CT) images. The PSIS is lateral to the pediculocorporeal screw direction line (black SP line), which allows safe and secure S1 screwing anteromedially from the superior articular S1 facet (S) during a posterior approach. P: promontorium.
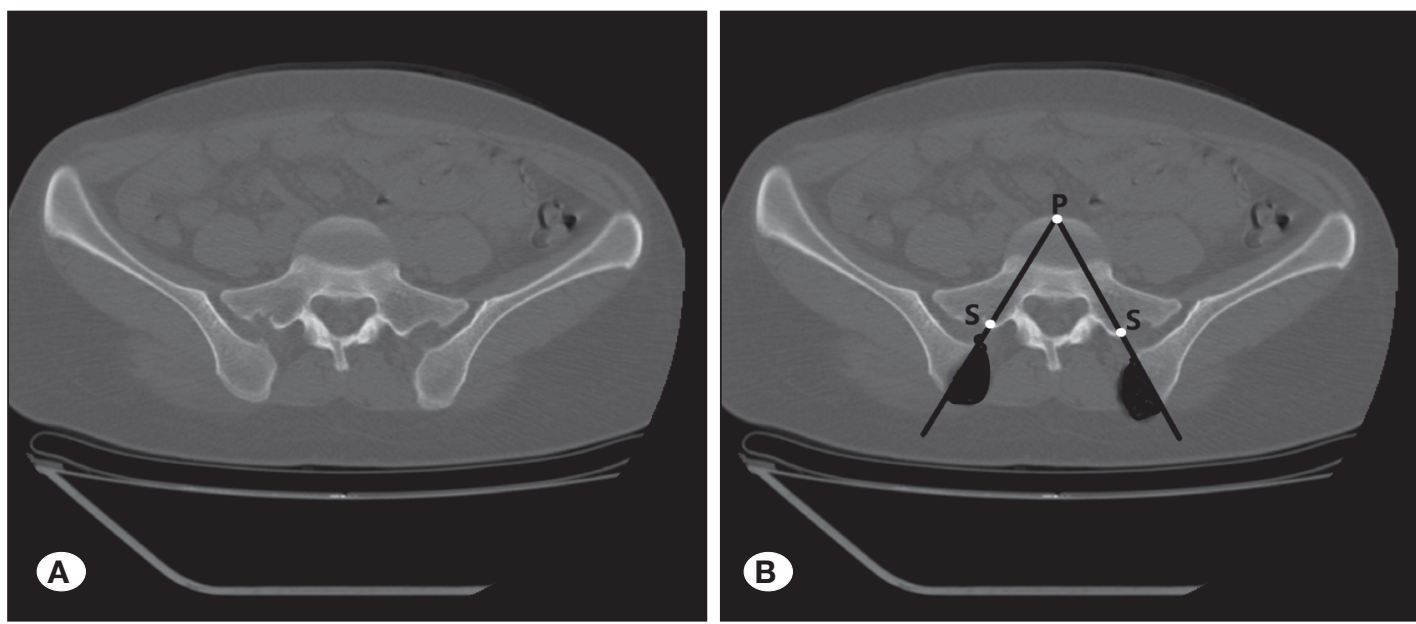

Figure 2: (A) and (B) (marked). Closed posterior superior iliac spine (PSIS) is shown in axial computed tomography (CT) images. The PSIS is very medial to the pediculocorporeal screw direction line (black SP line), making it unfeasible to insert an S1 screw anteromedially from the superior articular S1 facet (S) during a posterior approach. P: promontorium.

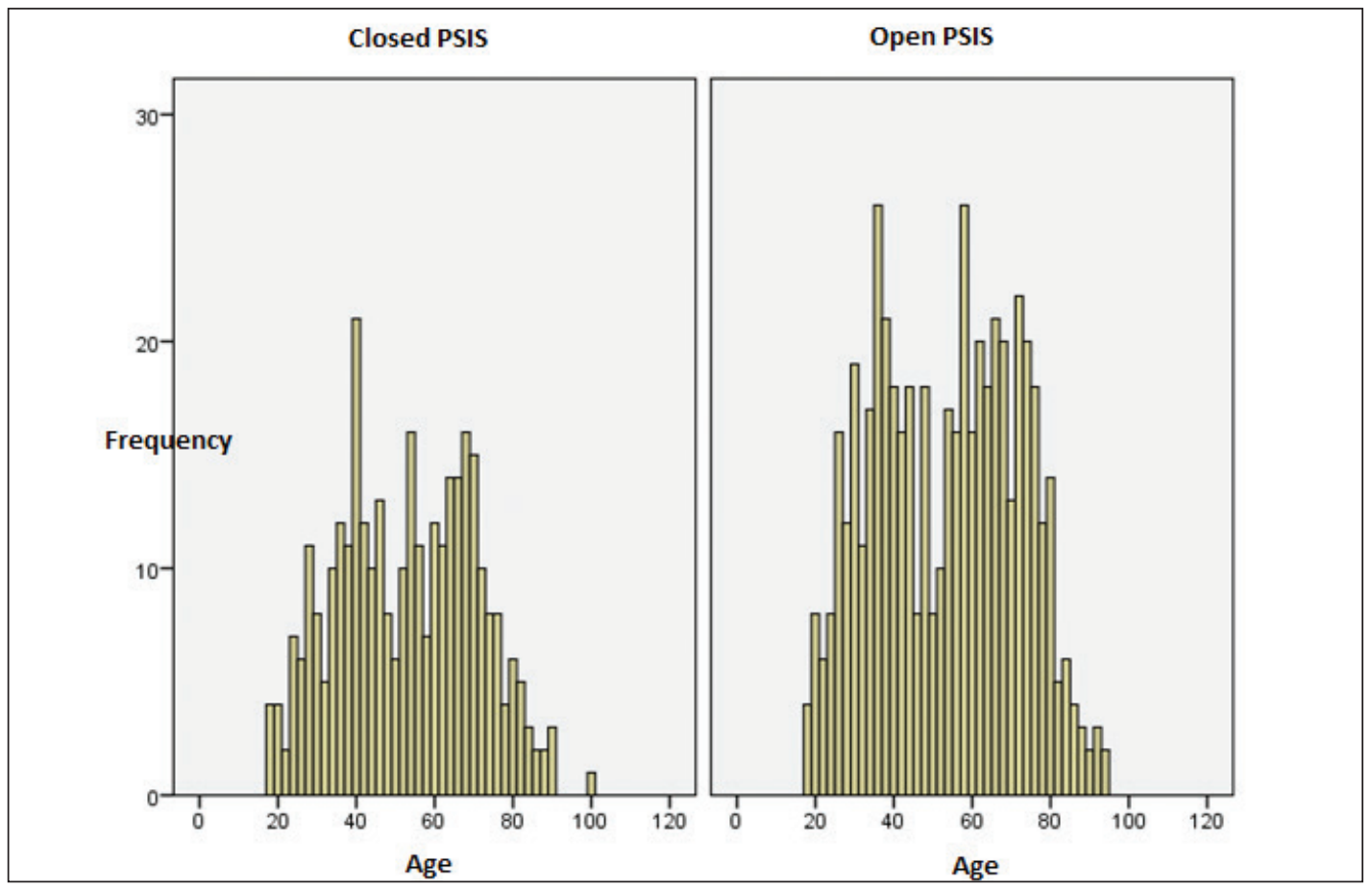

Figure 3: Distribution by age in both open and closed posterior superior iliac spine (PSIS) groups. Age is given in years. 


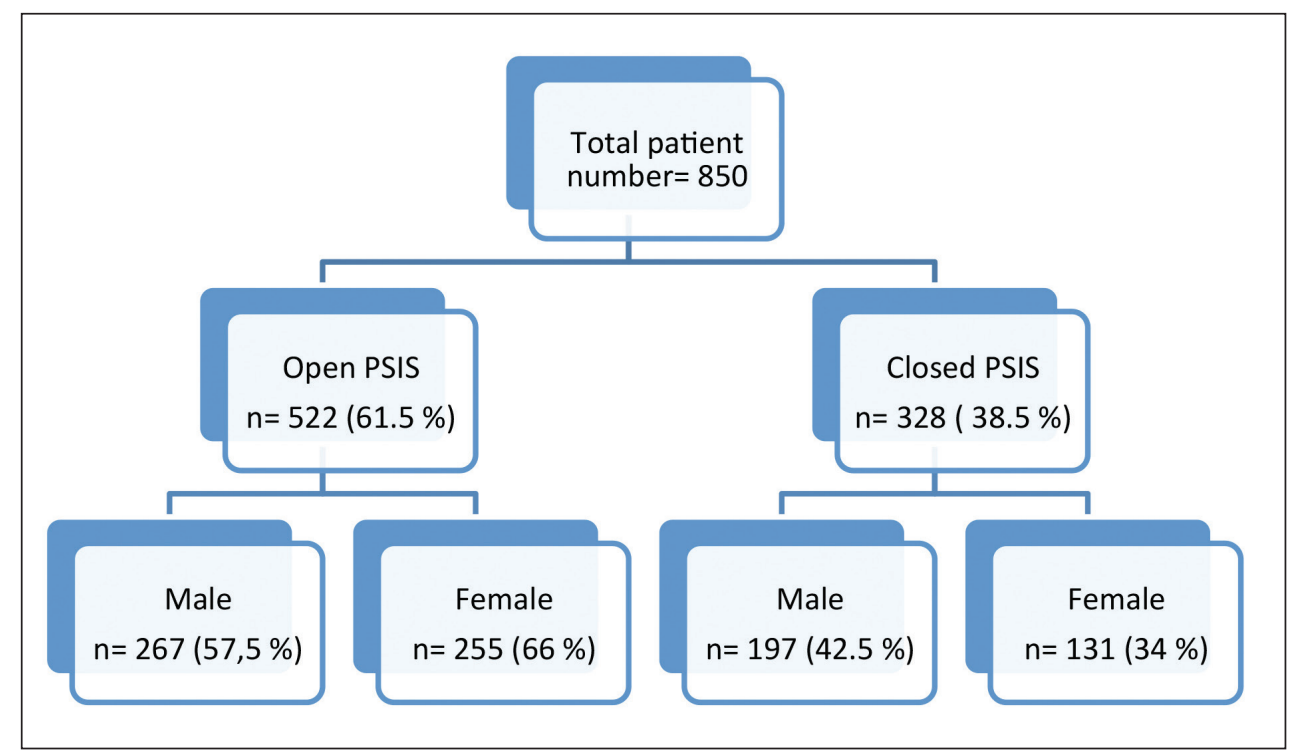

Figure 4: Frequency of open and closed posterior superior iliac spine (PSIS) and its distribution by gender. an anteromedial S1 screw direction is chosen for posterior fusion with rod-screw fixation, the screw should be inserted into the safe zone, through the promontory, and into the S1 vertebral body. To evaluate the presence of closed PSIS and the amount of iliac resection, CT scans should be acquired preoperatively.

\section{REFERENCES}

1. Carlson GD, Abitbol JJ, Anderson DR, Krag MH, Kostuik JP, Woo SL, Garfin SR: Screw fixation in the human sacrum. An in vitro study of the biomechanics of fixation. Spine 17:196-203, 1992

2. de Peretti F, Argenson C, Bourgeon A, Omar F, Eude P, Aboulker C: Anatomic and experimental basis for the insertion of a screw at the first sacral vertebra. Surg Radiol Anat 13:133137, 1991

3. Ebraheim NA, Lu J, Biyani A, Galluch D, Yang H, Yeasting RA: Location of the first and second sacral nerve roots in relation to pedicle screw placement. Am J Orthop (Belle Mead NJ) 29:873-877, 2000

4. Ebraheim NA, Mermer M, Xu R, Yeasting RA: Radiological evaluation of S1 dorsal screw placement. J Spinal Disord 9:527-535, 1996

5. Harrington PR, Dickson $\mathrm{JH}$ : Spinal instrumentation in the treatment of severe progressive spondylolisthesis. Clin Orthop Relat Res 157-163, 1976

6. Kaptanoglu E, Okutan O, Tekdemir I, Beskonakli E, Deda $\mathrm{H}$ : Closed posterior superior iliac spine impeding pediculocorporeal S-1 screw insertion. J Neurosurg 99:229234, 2003

7. Kornblatt MD, Casey MP, Jacobs RR: Internal fixation in lumbosacral spine fusion. A biomechanical and clinical study. Clin Orthop Relat Res 141-150, 1986
8. Kostuik JP, Errico TJ, Gleason TF: Techniques of internal fixation for degenerative conditions of the lumbar spine. Clin Orthop Relat Res 219-231, 1986

9. Krag MH, Van Hal ME, Beynnon BD: Placement of transpedicular vertebral screws close to anterior vertebral cortex. Description of methods. Spine 14:879-883, 1989

10. Louis R: Fusion of the lumbar and sacral spine by internal fixation with screw plates. Clin Orthop Relat Res 203:18-33, 1986

11. Lu J, Ebraheim NA, Yang H, Heck BE: Anatomic evaluation of the first three sacral vertebrae and dorsal screw placement. Am J Orthop (Belle Mead NJ) 29:376-379, 2000

12. Mirkovic S, Abitbol JJ, Steinman J, Edwards CC, Schaffler M, Massie J, Garfin SR: Anatomic consideration for sacral screw placement. Spine 16:289-294, 1991

13.Newman-Sanders A, Hine A: The musculoskeletal system 2: The lower limb. In: Butler P, Mitchell A, Ellis, H (ed), Applied Radiological Anatomy. Cambridge: Cambridge University Press, 1999:351-380

14. Roy-Camille R, Saillant G, Mazel C: Internal fixation of the lumbar spine with pedicle screw plating. Clin Orthop Relat Res 203:7-17, 1986

15. Steffee AD, Biscup RS, Sitkowski DJ: Segmental spine plates with pedicle screw fixation. A new internal fixation device for disorders of the lumbar and thoracolumbar spine. Clin Orthop Relat Res 203:45-53, 1986

16. von Strempel A, Trenkmann S, Kronauer I, Kirsch L, Sukopp C: The stability of bone screws in the os sacrum. Eur Spine J 7:313-320, 1998

17. White AH, Zucherman JF, Hsu K: Lumbosacral fusions with Harrington rods and intersegmental wiring. Clin Orthop Relat Res 203:185-190, 1986 